\title{
Restorative Approach in Prosthetic Rehabilitation of Unilaterally Resorbed Maxillary Edentulous Ridge and Partly Resorbed Mandibular Edentulous Ridges: A Case Report
}

\author{
Srdjan D. Poštić \\ Department of Prosthodonics, Faculty of Dental Medicine, University of Belgrade, Belgrade, Serbia
}

\begin{abstract}
SUMMARY
Introduction The aim of this study was to fabricate a complete upper acrylic denture and a partial lower acrylic denture and provide occlusal rehabilitation with added benefit of correcting the position of altered condyle in a dysfunctional stomatognathic system.

Case Report Procedures for fabrication of acrylic dentures are thoroughly described. Specific scheme of occlusion was applied in the treatment of this patent. Occlusal contacts were established as tripod minor contacts on the side where the part of upper edentulous ridge was intensively reduced (on the right side) with divergent tracing of the condyle due to dysfunction. Tripod contacts were established on occlusal surfaces of opposing teeth as well. Contacts on the left side were formed as circumferential surfaces. Specially distributed occlusal contacts favorably influenced reduction of occlusal stresses on supporting tissues in the mouth of the patient. Tooth contacts arranged in such particular order were established to redistribute loading as well as to prevent excessive propulsion and latero-protrusive movements of the lower jaw.

Conclusion Occlusal pattern of tripod and single-point contacts was used to compensate differences in condylar movements of this patient with stomatognathic dysfunction, intending to diminish loads on reduced surfaces.
\end{abstract}

Keywords: dysfunction of stomatognathic system; edentulous; mandible; occlusion

\section{INTRODUCTION}

Unilaterally insufficient supporting surface of edentulous maxilla may cause problems in therapy because of excessive loading in supporting areas in the function of stomatognathic system. Literature contains discussions on the therapeutic approach for partially and completely edentulous patients requiring acrylic dentures not only in cases where complete upper denture is indicated, but also in cases where both, complete upper denture and partial acrylic lower denture are required [1, 2, 3-6]. Literature data has indicated the importance of modifying occlusal patterns, occlusal loading in function, and condition of supporting tissues [1-8].

The aim of this work was to fabricate and position a complete acrylic upper denture and a partial acrylic lower denture and provide occlusal rehabilitation with added benefit of correcting the position of the altered condyle in a dysfunctional stomatognathic system.

\section{CASE REPORT}

A 51-year-old patient showed up at the Department of Prosthodonics, Faculty of Dental Medicine, University of Belgrade, because of difficulties in his stomatognathic system and teeth loss. On the clinical examination, mandibular deviation during mouth opening and lateral mandibular movements was observed on the right side and noted. The treatment plan for this patient was to make a complete acrylic upper denture and a partial acrylic lower denture with specific occlusal scheme.

Preliminary impressions of edentulous maxilla and partially edentulous mandible were performed using alginate (Alginogal, Galenika, Serbia) in properly designed, standard metal trays. The impressions were poured with plaster. Border areas and extension surfaces were marked on the surface of preliminary impressions. Preliminary maxillary and mandibular casts were formed. By assessing mucous supporting areas of the jaws and border areas of preliminary casts, the outline for the custom tray was determined. Maxillary and mandibular custom trays were formed (Palavit L, Galenika, Serbia). After try-in, a stick modeling compound, thermoplastic material for peripheral seal formation (Kuprovent, Galenika, Serbia) was heated, tempered, and added in sections on the border surfaces of acrylic custom trays. The tempered thermoplastic mass was shaped and positioned in mouth.

The final maxillary impression was done using zinc oxide - eugenol impression paste (Coe-Flo impression 
cream, Coe Laboratories Inc, Chicago, Ill. USA). The final mandibular impression was taken using elastomer-silicone impression material (Oranwash, Zherrmack, Germany) and zinc oxide and eugenol impression paste (VIKOPRES, $\mathrm{ZnO}$-eugenol, Galenika, Serbia) at the same time in the custom tray. Master casts were fabricated using hard stone (Gipsogal dental stone, type 3, Galenika, Serbia). Baseplates (Bazogal, Galenika, Serbia) were adapted on the surface of master casts, and occlusal rims were outlined.

A facebow fork was inserted in wax of the upper occlusal rim. The facebow was positioned after the region of condyle was marked on the face of the patient, then the registration was completed (Figure 1). The face-bow and the fork were attached to the articulator (Dentatus ARLS, Dentatus, Sweden) and the maxillary cast was mounted in it using plaster (Figure 2).

Blunt end of a grading instrument was positioned the on mucosal supporting surfaces in order to assess their resilience (Figure 3a). Numerical values of resilient surfaces were: $0.85 \mathrm{~mm}$ of fluctuant supporting surface in edentulous maxilla, $0.2 \mathrm{~mm}$ of fluctuant edentulous supporting surface on the left side of mandible, and the average of $0.25 \mathrm{~mm}(0.2 \mathrm{~mm} ; 0.25 \mathrm{~mm} ; 0.3 \mathrm{~mm})$ resilient fluctuant edentulous supporting surface on the right side of mandible (Figure 3b).

Occlusal rims were formed, positioned in the mouth, and depending on the state of resilience of supporting areas, the final centric record was made (Figure 4). Mandibular cast was positioned in the articulator according to the centric record. After the casts were mounted in the articulator, the values of protrusive condylar paths were determined using lateral wax records. Wax records were created using dental wax (Vomogal C, medium hardness modeling wax plates, Galenika, Serbia) and adapted. Positions of the patient's mandible were recorded in protrusion and right and left lateral excursions (Figures 5a and $5 b$ ). Condylar paths were adjusted according to the wax records in the articulator. Discrepancies in sagittal inclinations were as follows: sagittal right inclination $24^{\circ}$; sagittal left inclination $35^{\circ}$. In accordance with eccentric wax-records, Bennett's angle on the right was adjusted to $12^{\circ}$ and on the left to $7^{\circ}$ (Figure 6).

Artificial acrylic teeth (anterior teeth OPTODENT; posterior teeth OPTOGNATH; Bayer-Galenika, Galenika, Serbia), color 36, were selected. Try-in was performed in two phases: positioning of anterior teeth was first done, and rechecking of condylar relationships and centric record were conducted. With respect to resorption, supporting tissue condition, protrusive and lateral jaw movements and relationships, specific occlusal contacts and guidance were planned.

In addition, posterior artificial teeth were positioned onto wax surfaces. Double-sided, $80 \mu \mathrm{m}$ articulating paper in two colors (red and blue) was applied to create occlusal contacts. They were established as minor tripod contacts on the side where part of the maxillary edentulous ridge was extensively resorbed toward the distal border. Tripod contacts were provided on the opposing occlusal surfaces of the corresponding teeth as well. Contacts on the left side were formed as circumferential surfaces (Figures 7 and 8).
During the simulation of jaw movements, guiding tracings were formed as identical lines out of tripod contacts and identical small triangles apart from circumferences on opposite occlusal surfaces on the left side (Figure 9). Occlusal contacts were analyzed in terms of condylar guidance.

Try in was performed and jaw relationships were rechecked. Occlusal contacts were checked in centric position. Articulating paper of $80-\mu \mathrm{m}$ thickness was used to mark possible occlusal contacts (Figure 10). Occlusal contacts were also checked in protrusive and lateral jaw movements (Figure 11).

Trial upper and lower denture bases with complete setup of artificial teeth were positioned on the respective master casts. Occlusal contacts were determined according to the patient's records, using condylar positions and guidance that were provided by adjusting the elements of the articulator (Figure 12). Trial bases with complete set-up of teeth were positioned to add veneers on anterior teeth in order to establish anterior guidance and provide for completion of waxing and flasking.

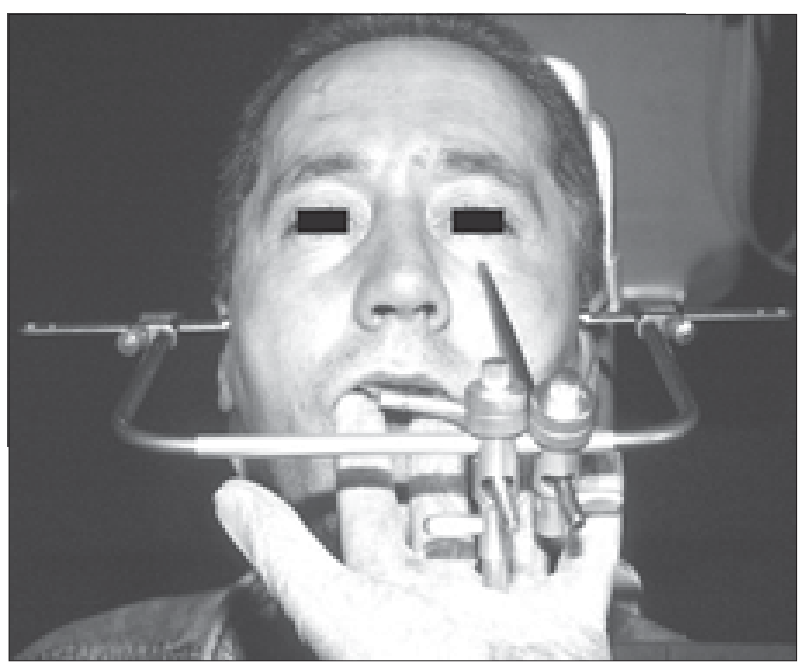

Figure 1. Face-bow positioned according to the reference points Slika 1. Obrazni luk postavljen prema referentnim tačkama

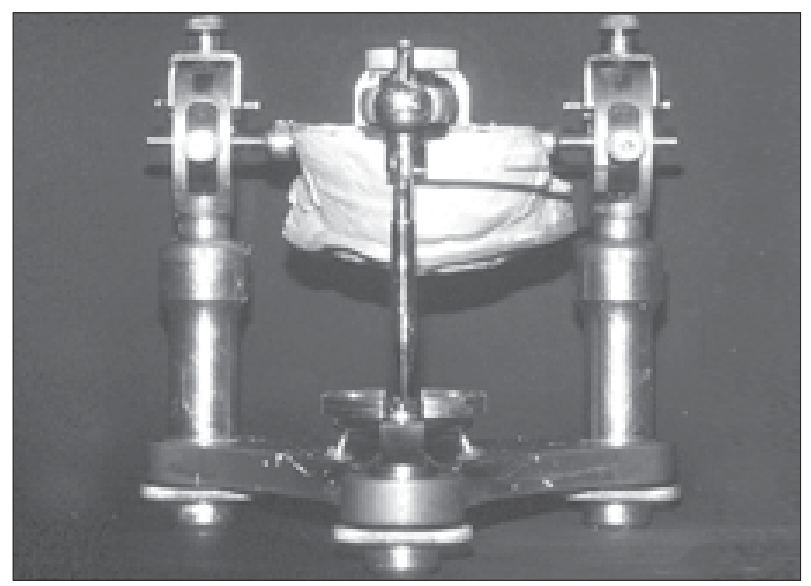

Figure 2. Master cast of edentulous maxilla positioned in the semiadjustable articulator after the completion of face-bow transfer Slika 2. Radni model bezube gornje vilice postavljen u polupodesivi artikulator posle završenog prenosa pomoću obraznog luka 


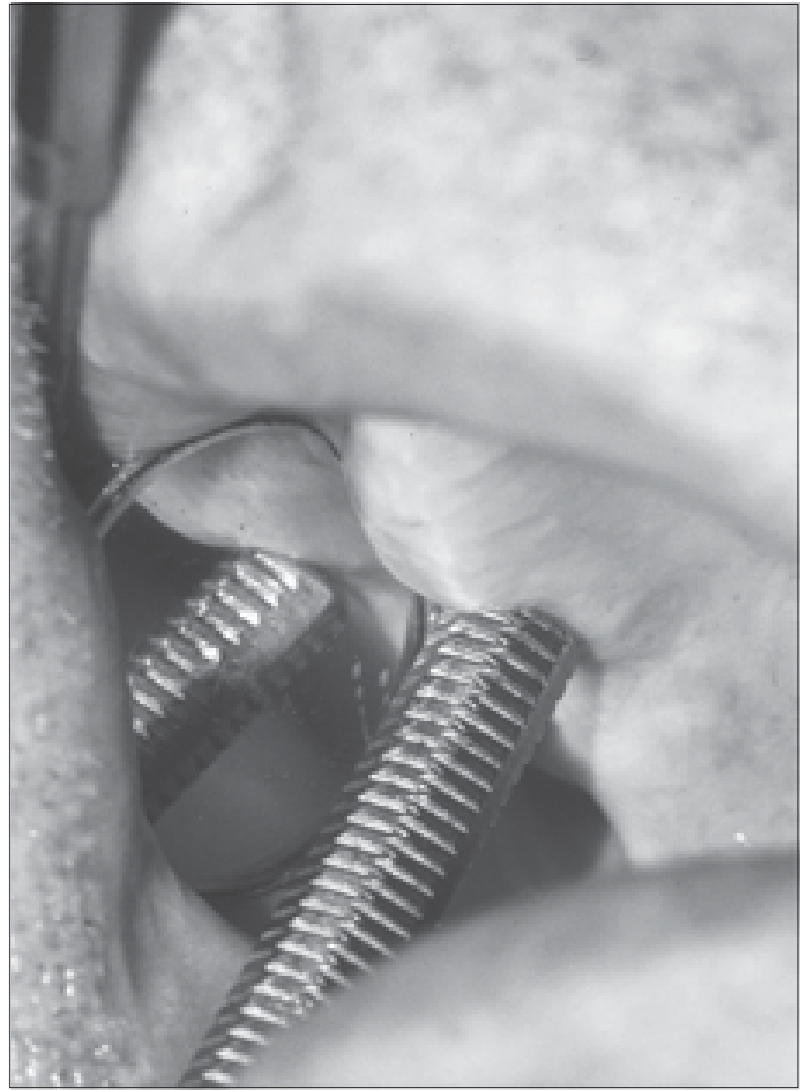

Figure 3a. The assessment of supporting mucosal surface resiliency of upper edentulous residual ridge

Slika 3a. Ispitivanje rezilijentnosti nosećih tkiva i mukoze po bezubom gornjem grebenu

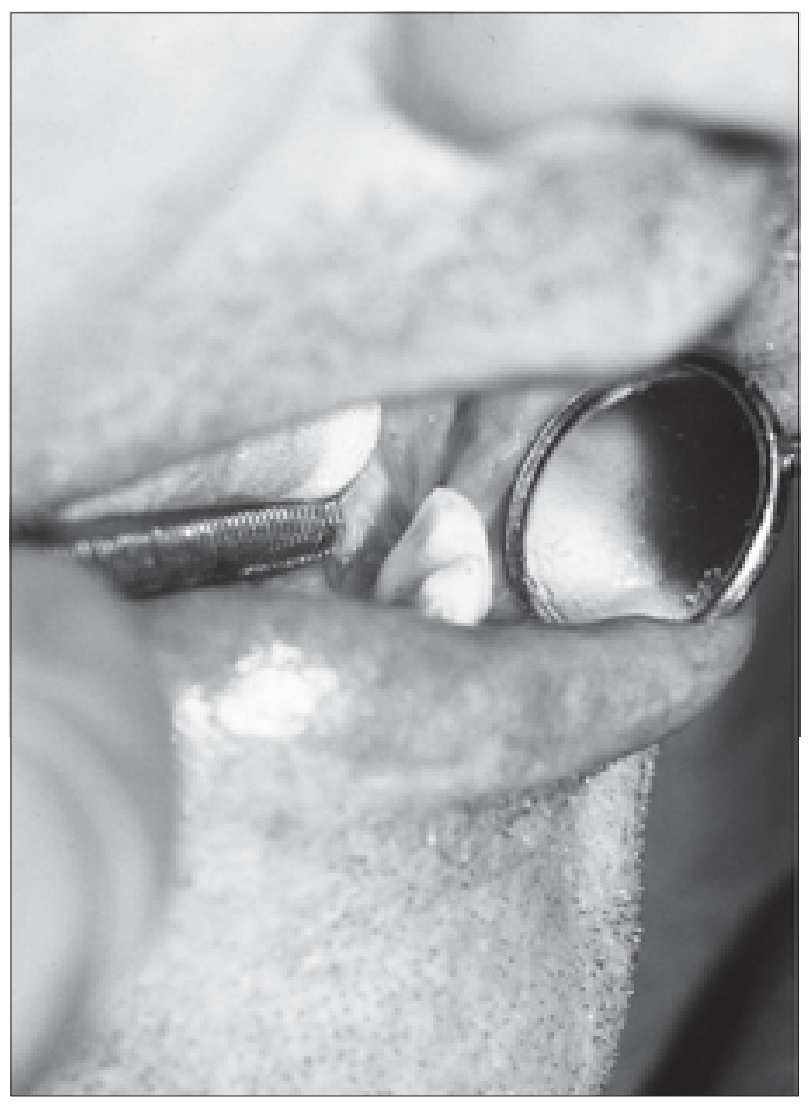

Figure $\mathbf{3 b}$. The measurement of edentulous supporting surface resiliency on the right side of the lower jaw

Slika 3b. Merenje rezilijentnosti bezubih nosećih tkiva na desnoj strani donje vilice

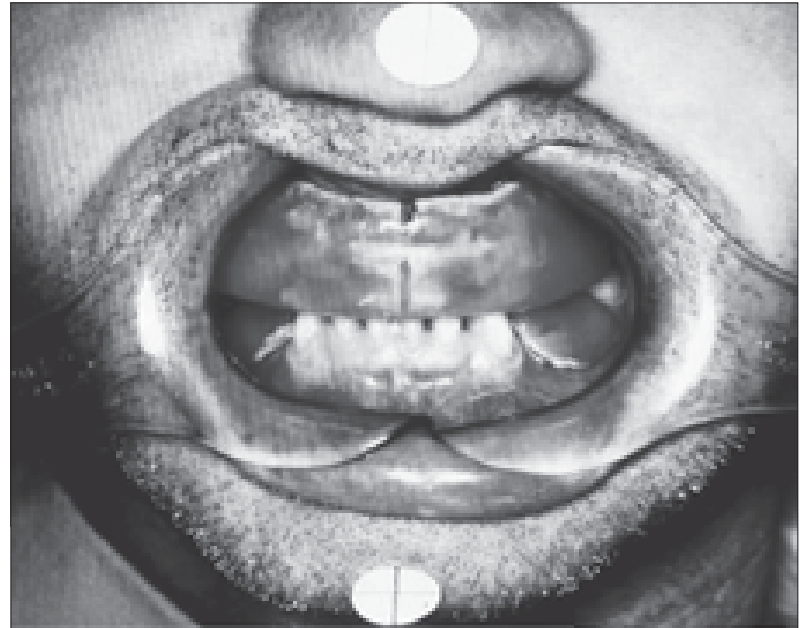

Figure 4. Established centric record of occlusal rims positioned in the mouth in accordance with resilient supporting areas

Slika 4. Ustanovljen centralni odnos gornje i donje zagrižajne šablone u ustima u skladu s rezilijentnošću mukoze na nosećim tkivima

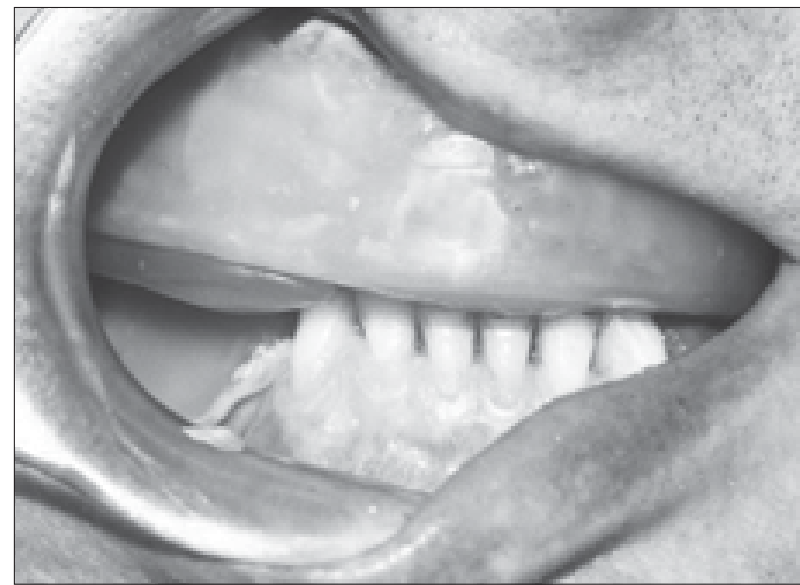

Figure 5a. Eccentric mandibular position registration using wax Slika 5a. Registracija ekscentričnog polozaja donje vilice pomoću pozicionog registrata

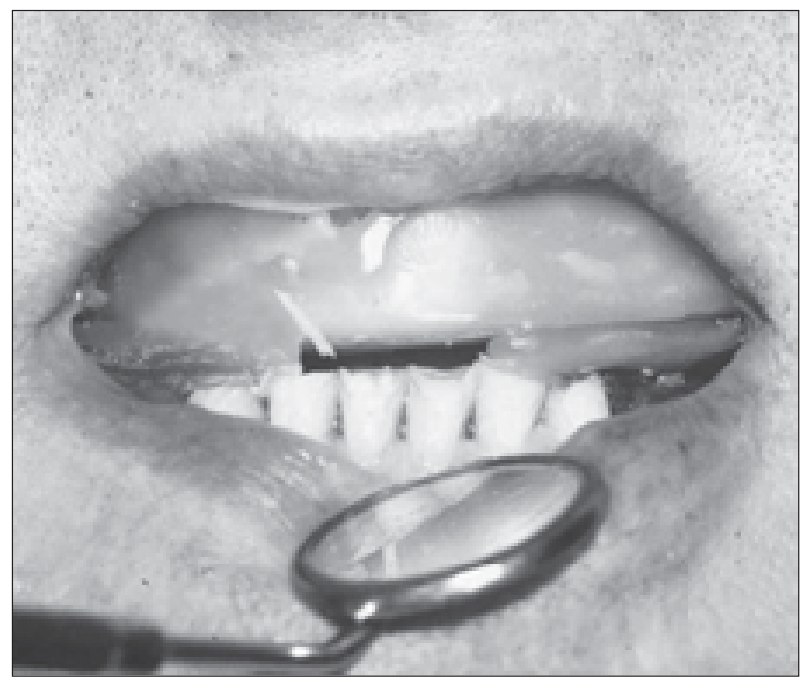

Figure 5b. Protrusive interocclusal record Slika 5b. Pozicioni registrati postavljeni u propulziji 


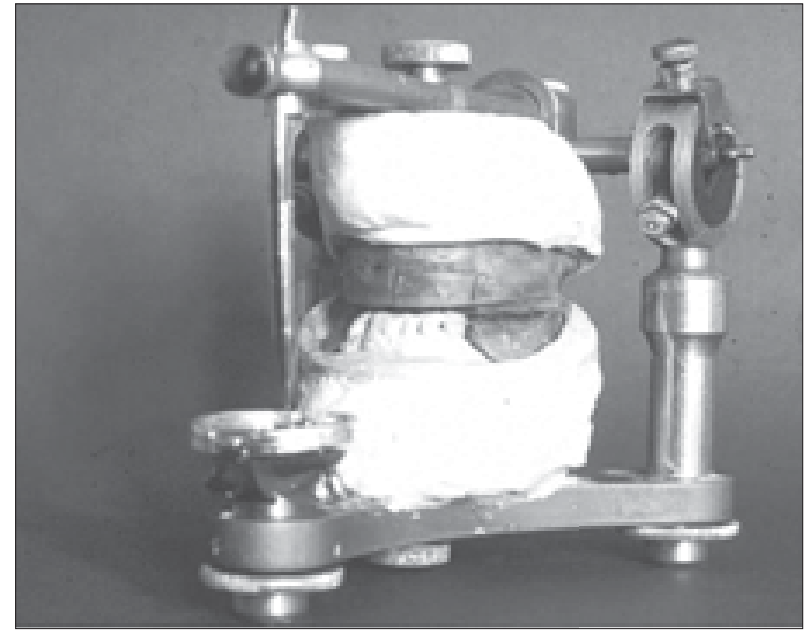

Figure 6. Condylar elements of the articulator adjusted to saggital right inclination of $24^{\circ}$, saggital left inclination of $35^{\circ}$, Bennett's angle on the right to $12^{\circ}$, and on the left to $7^{\circ}$

Slika 6. Kondilni elementi artikulatora podešeni na desnoj strani do inklinacije od $24^{\circ}$, na inklinaciju od $35^{\circ}$ na levoj strani i Benetovim uglom od $12^{\circ}$ na desnoj strani i $7^{\circ}$ na levoj strani

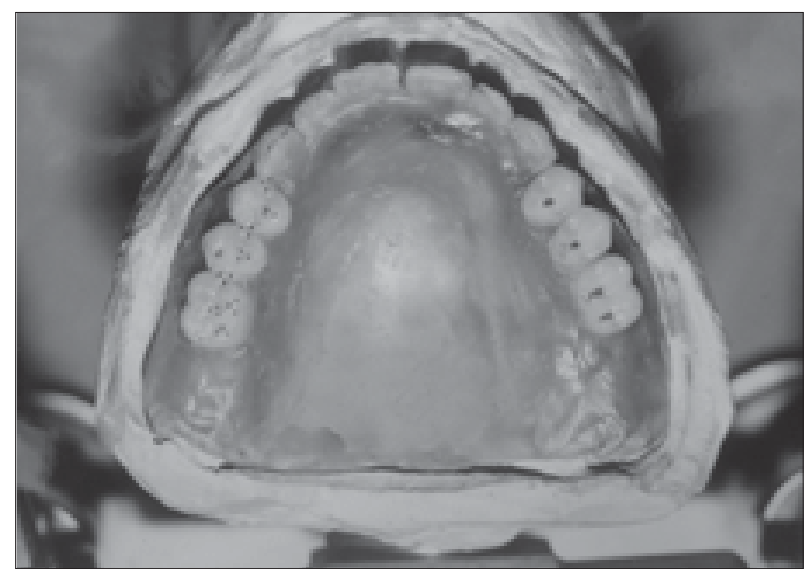

Figure 7. Tripod contacts on dysfunctional side and circumferential contacts on the opposite side with gliding tracings

Slika 7. Tripodni kontakti na stani gde postoji disfunkcija i periferni kontakti na suprotnoj strani s formiranim putanjama pri kliznim kretnjama donje vilice

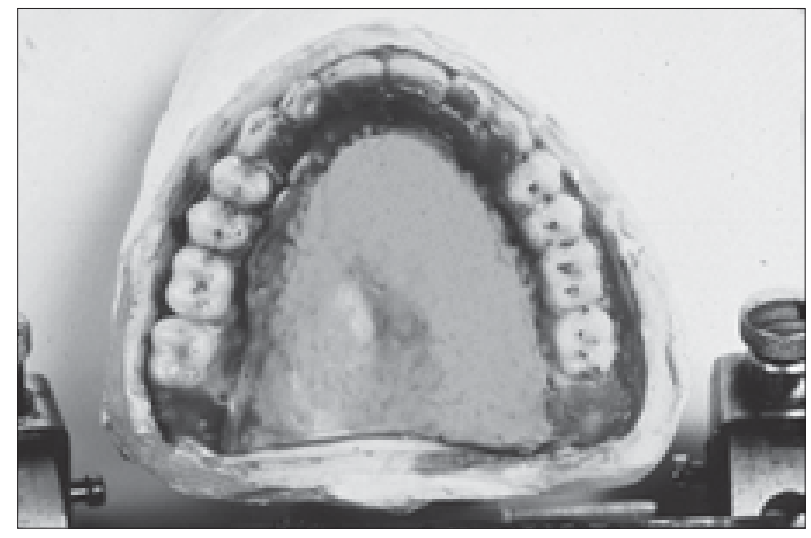

Figure 8. Occlusal contacts established as minor tripod contacts on the side where upper edentulous ridge was intensively reduced towards distal parts

Figure 8. Okluzivni kontakti ustanovljeni u obliku tripodnih kontakata na strani gde je bezubi gornji greben bio intenzivno resorbovan ka distalnim delovima

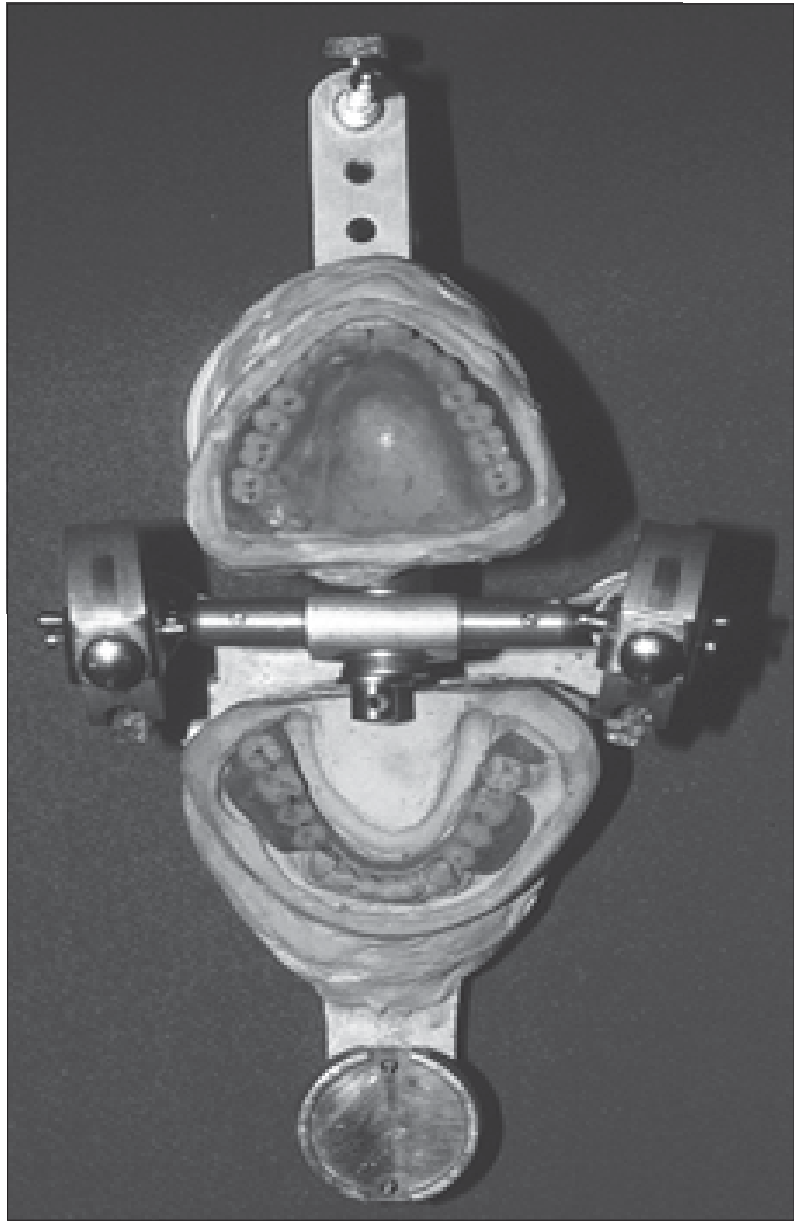

Figure 9. Occlusal contacts established in accordance to the condylar guidance with guiding tracings formed as lines out of tripod contacts and triangle like tracings around circumferential contacts on opposite occlusal surfaces

Slika 9. Okluzivni kontakti ustanovljeni u skladu s kondilnim vođenjem, vodeće putanje pri kliznim, linijskim kontaktima izvan tripodnih kontakata i trouglaste putanje malih dimenzija oko perifernih kontakata na okluzivnim površinama zuba antagonista

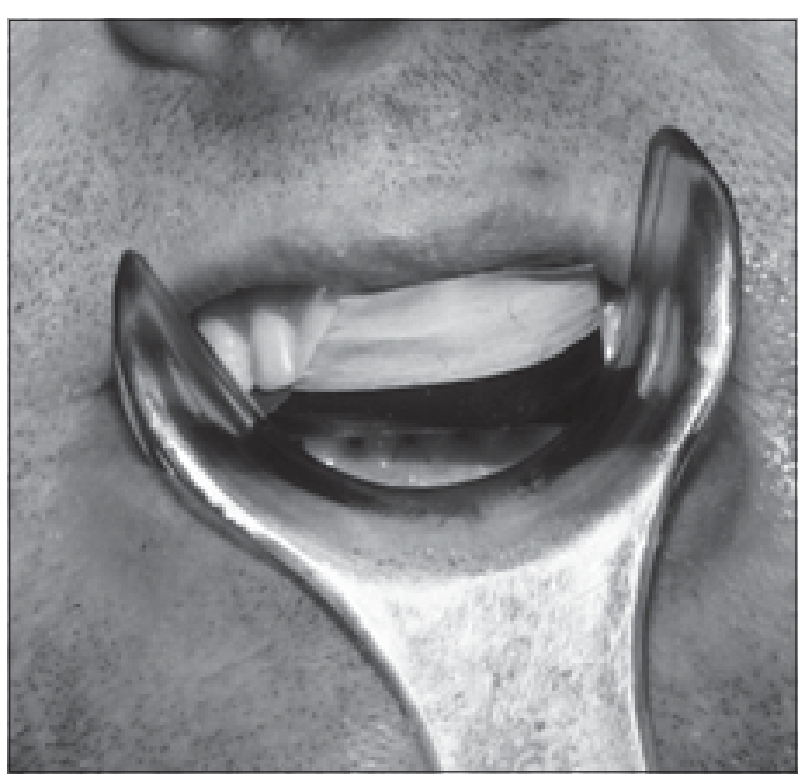

Figure 10. Two-colored articulating paper positioned in the mouth for checking occlusal contacts in centric position

Slika 10. Dvobojna artkulaciona hartija postavljena u ustima zbog provere okluzivnih kontakata u centralnom položaju 


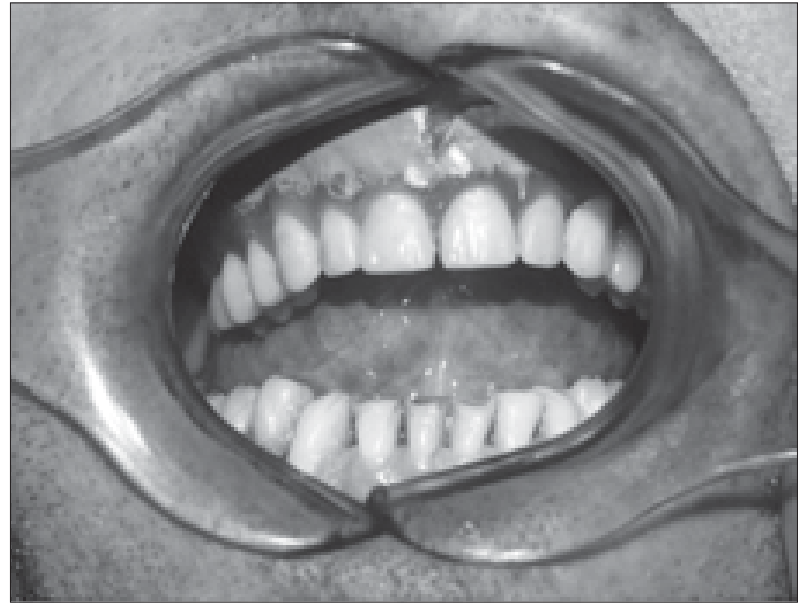

Figure 11. Occlusal contacts marked in protrusive and lateral mandibular movements

Slika 11. Okluzivni kontakti označeni u propulziji i pri lateralnim kretnjama donje vilice

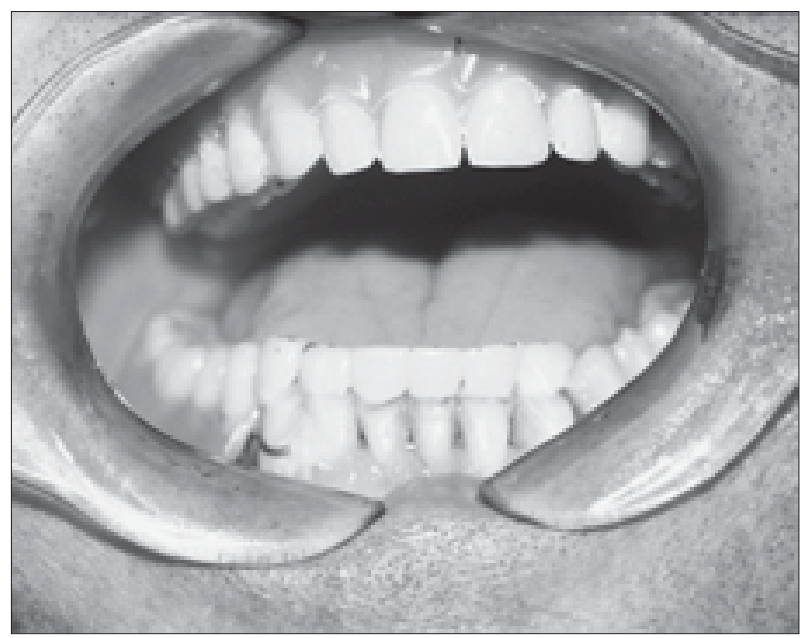

Figure 12. Facets on the lower anterior artificial teeth to establish anterior guidance

Slika 12. Postavljene fasete na donjim prednjim zubima zbog ostvarivanja prednjeg vođenja

\section{DISCUSSION}

According to the literature, forces generated on occlusal surfaces within artificial teeth in complete dentures should be symmetrically and uniformly distributed during stomathognathic system functions $[1,2,6]$. Symmetric loads on determined areas of occlusal surfaces should exist not only in the position of maximum intercuspation, but in gliding tooth contacts in lateral and protrusive movements $[1,2,3,7]$. However, in certain clinical situations, modifications of occlusal patterns are required to change the position of contacts, particularly when making gliding movements in lateral excursions. After observing the patient's stomathognathic system at the beginning of therapy, specific condylar guidance was established to modify positions of gliding contacts on occlusal surfaces of artificial teeth $[2,5,7]$.

There is some time particular need to determine flat contacts on occlusal surfaces and to combine specific broad segments with specific, less steep and restricted parts within the occlusal tracings of corresponding occlusal surfaces, especially in instances of supporting tissue resorption and condylar imbalance. This is why the occlusal scheme herein diverges from regular scheme of artificial occlusion in acrylic dentures in which tooth contacts are organized according to the single-point contact scheme with respect to the surfaces of central fossa, marginal ridges, and supporting cusps.

It was intended herein to provide adequate redistribution of functional loading on occlusal surfaces of artificial dental arches by analyzing specific forms of supporting surfaces. Specific distribution of occlusal contacts on the right side and different occlusal scheme on the left were used for undeviating occlusal direction on the right side and straight occlusal guidance on the left, but with exception to uniform and symmetric occlusal pattern. Applying a specific occlusal scheme meant that occlusal stresses would be more favorably applied to supporting tissues, and they would reposition altered condyle on the working side $[5,9,10]$.

In restoring this patient's dentition with acrylic dentures, an accessory occlusal plate in the form of incisal edges and occlusal surfaces of composite-occlusal overlay, was added to the occlusal scheme of the lower acrylic denture to correct the relationship of existing mandibular anterior teeth.

Particularly distributed occlusal contacts favorably influence reduction of occlusal stresses on supporting tissues in the mouth. In this case, tooth contacts were arranged so to redistribute loading, as well as to prevent excessive propulsion and latero-protrusive mandibular movements. Occlusal pattern of tripod and single-point contacts was used to compensate differences in condylar movements of this patient with stomatognathic dysfunction and to reduce loads on resorbed surfaces.

\section{REFERENCES}

1. Zarb GA, Bolender Cl, Eckert SE, Fenton AH, Jacob RF, MericskeStern R. Prosthodontic Treatment for Edentulous Patients. 12th ed. St. Louis: Mosby; 2004.

2. Dowson PE. Evaluation, Diagnosis and Treatment of Occlusal Problems. St. Louis: Mosby Co; 1989.

3. Gross MD, Mathews J. Occlusion in Restorative Dentistry. Edinburgh: Churchill Livingstone; 1982.

4. Mohl ND, Zarb GA, Carlsson G, Rugh JD. A Textbook of Occlusion. Chicago: Quintessence Publ. Co. Inc; 1988.

5. Mongini F. The Stomatognathic System: Function, Dysfunction and Rehabilitation. Chicago: Quintessence Publ. Co. Inc; 1984.

6. Poštić SD, Krstić MS, Teodosijević MV. A comparative study of the chewing cycles of dentate and denture wearing subjects. Int J Prosthodont. 1992; 5:244-56.

7. Ramfjord S, Ash MM. Occlusion. Philadelphia: WB Sounders Co; 1983.

8. Thomson H. Occlusion. Bristol: John Wright; 1975.

9. Bell WE. Temporomandibular Disorders. Classification, Diagnosis, Management. 3rd ed. Chicago: Year Book Medical Publishers; 1990.

10. McNeill C, American Academy of Craniomandibular Disorders. Craniomandibular Disorders: Guidelines for Evaluation, Diagnosis, and Management. Chicago: Quintessence Publishing Inc; 1990. 


\title{
Terapijski pristup u rehabilitovanju jednostrano resorbovanog grebena gornje vilice i delimično resorbovanih grebenova donje vilice - prikaz slučaja
}

\author{
Srđan D. Poštić \\ Klinika za stomatološku protetiku, Stomatološki fakultet, Univerzitet u Beogradu, Beograd, Srbija
}

\begin{abstract}
KRATAK SADRŽAJ
Uvod Cilj rada je bio da se prikaže postupak izrade gornje akrilatne totalne proteze i donje akrilatne parcijalne proteze, kojima je obezbeđena rehabilitacija okluzije kod pacijenta s korigovanjem položaja izmenjenog kondila usled disfunkcije njegovog stomatognatog sistema.

Prikaz slučaja $U$ radu su detaljno prikazani postupci u izradi akrilatnih proteza. $U$ terapiji pacijenta je primenjena specifična shema okluzije, pri čemu su uspostavljeni tripodni okluzivni kontakti malih dimenzija na strani gde je greben intenzivno resorbovan i gde je postojalo deviranje kondila usled disfunkcije. Tripodni tačkasti kontakti su uspostavljeni i na okluzivnim površinama zuba antagonista. Kontakti zuba na suprotnoj, levoj strani su uspostavljeni kao kružne linije po ograničenim malim površinama. Posebno raspoređeni kontakti zuba povoljno utiču na smanjenje pritiska na nosećim tkivima u ustima pacijenta. Kontakti zuba uspostavljeni na ovakav način rasterećuju i sprečavaju prekomernu propulziju i lateropropulzivne pokrete donje vilice.

Zaključak Posebno ustanovljena i primenjena shema okluzije i tačkasti kontakti su u terapiji primenjeni da bi se kompenzovale razlike u pokretima kondila usled disfunkcije stomatognatog sistema i smanjilo opterećenje na redukovani greben.
\end{abstract}

Ključne reči: disfunkcija stomatognatog sistema; bezubost; mandibula; okluzija

\section{UVOD}

Jednostrano insuficijentna noseća površina tkiva bezube gornje vilice može biti problem u terapiji zbog neželjenih i povećanih opterećenja nosećih tkiva u funkciji stomatognatog sistema pacijenata. U stručnoj literaturi navode se brojne dileme u vezi s pristupom u terapiji osoba bez zuba ili s malim brojem zuba kod kojih je indikovana izrada akrilatnih proteza, ne samo kada treba rehabilitovati bezube vilice, već i kada je u skladu s planom terapije potrebno postavljanje i gornje totalne zubne proteze i donje parcijalne akrilatne pločaste proteze $[1,2,3-6]$. Podaci iz stručne literature takođe ukazuju na značaj modifikovanja sheme okluzije, okluzivnog opterećenja u funkciji i stanja nosećih tkiva ispod proteza [1-8].

Cilj ovog rada bio je da se prikaže postupak izrade gornje akrilatne totalne proteze i donje akrilatne parcijalne proteze, kojima je obezbeđena rehabilitacija okluzije kod pacijenta $s$ korigovanjem položaja izmenjenog kondila usled disfunkcije njegovog stomatognatog sistema.

\section{PRIKAZ SLUČAJA}

Muškarac star 51 godinu javio se u Kliniku za stomatološku protetiku Stomatološkog fakulteta Univerziteta u Beogradu zbog smetnji u funkciji stomatognatog sistema i teškoća usled krezubosti, odnosno bezubosti. Tokom kliničkog pregleda uočeno je skretanje mandibule pri otvaranju usta i pri lateralnim kretnjama na radnoj desnoj strani. Plan terapije je bio da se izradi akrilatna gornja totalna zubna proteza i parcijalna donja akrilatna proteza s izmenjenom i specifičnom shemom okluzije, te proteze postave u usta pacijenta.

Bezuba gornja vilica i bezuba donja vilica su preliminarno otisnute alginatom (Alginogal, Galenika, Srbija) u odgovarajućim metalnim standardnim kašikama. Preliminarni otisci bezube gornje vilice i krezube donje vilice su izliveni gipsom.
Granice individualnih kašika su označene po površinama preliminarnih otisaka. Na osnovu preliminarnih otisaka su izrađeni anatomski modeli gornje i donje vilice. Ispitujući mukozu i noseća tkiva vilica i procenjujući granice pokretne i nepokretne sluzokože na preliminarnim - anatomskim modelima utvrđeno je dokle treba postaviti akrilat od kojeg će biti izrađene individualne kašike, i zatim ukloniti viškove. Individualne kašike za gornju i donju vilicu su izrađene od akrilata (Palavit L, Galenika, Srbija). Nakon završetka probe individualnih kašika, po ivicama i graničnim površinama kašika naneta je zagrejana termoplastična masa (Kuprovent, Galenika, Srbija). Ona je adaptirana na ventilnim rubovima u ustima pacijenta.

Konačan, funkcijski otisak bezube gornje vilice je urađen cink-oksid-eugenol pastom (Coe-Flo impression cream, Coe Laboratories Inc, Chicago, IL, USA). Konačan, funkcijski otisak donje vilice je urađen kombinovanjem elastomera i silikonskog materijala (Oranwash, Zherrmack, Germany, EU) i cink-oksideugenol paste (Vikopres, ZnO-eugenol, Galenika, Srbija) istovremeno u inidividualnoj kašici. Konačni radni modeli obe vilice izrađeni su od tvrdog gipsa (Gipsogal, tip 3, Galenika, Srbija).

Bazne šelak ploče (Bazogal, Galenika, Srbija) adaptirane su na površinama radnih modela od tvrdog gipsa, a zatim su oblikovani zagrižajni bedemi od voska.

Po završenom oblikovanju gornjeg zagrižajnog bedema u vosak je utisnuta zagrižajna viljuška. Obrazni luk je postavljen po završenom označavanju regiona centra rotacije kondila na licu pacijenta. Uspostavljen je odnos gornje vilice prema referentnim centrima rotacije kondila (Slika 1). Zagrižajna viljuška, utisnuta u zagrižajni bedem, i obrazni luk postavljeni su prema referentnim tačkama artikulatora (Dentatus ARLS, Dentatus, Sweden), a zatim je radni model gornje bezube vilice pomoću gipsa učvršćen uz gornju granu artikulatora (Slika 2).

Radi ispitivanja rezilijentnosti (elastičnosti, prilagodljivosti) nosećih tkiva, zaobljen vrh metalnog instrumenta sa stepenima je postavljen na površinu mukoze (Slika 3a). Numeričke vrednosti merenja rezilijentnosti nosećih tkiva bile su sledeće: 
ukupna elastičnost nosećih površina izmerena u nosećim tkivima gornje bezube vilice - $0,85 \mathrm{~mm}$; ukupna rezilijentnost izmerena u nosećim tkivima s leve strane donje vilice - $0,2 \mathrm{~mm}$; prosečna vrednost svih izmerenih rezilijentnosti $(0,2 \mathrm{~mm} ; 0,25$ $\mathrm{mm} ; 0,3 \mathrm{~mm}$ ) mukoze na nosećim površinama donje vilice na desnoj strani - 0,25 mm (Slika 3b).

Po završenom oblikovanju zagrižajnih bedema, zagrižajni šabloni su postavljeni u usta u usklađenom odnosu prema izmerenim vrednostima rezilijentnosti pacijenta i određeni su međuvilični odnosi u centralnom položaju donje vilice (Slika 4). Radni model donje vilice je pomoću gipsa učvršćen $u$ artikulatoru prema određenom centralnom položaju mandibule. Po završenom učvršćivanju modela u artikulatoru, vrednosti nagiba kondilnih putanja su ustanovljene na osnovu voštanih pozicionih registrata koji su utvrđeni u propulziji i pri lateralnim položajima vilice. Oblici voštanih registrata su načinjeni korišćenjem dentalnog voska (Vomogal C, Galenika, Srbija). Položaji donje vilice pacijenta su ustanovljeni u propulziji, pri njenom pomeranju udesno i pri pomeranju ulevo (Slike 5a i 5b). Na osnovu voštanih registrata su podešeni nagibi kondilnih putanja $\mathrm{u}$ artikulatoru. Sagitalna inklinacija na desnoj strani bila je $24^{\circ}$, a na levoj strani $35^{\circ}$. U skladu s ekscentričnim voštanim registratom pri lateralnoj kretnji, Benetov ugao na desnoj strani je podešen na vrednost od $12^{\circ}$, a na levoj na vrednost od $7^{\circ}$ (Slika 6).

Veštački akrilatni zubi (prednji zubi Optodent; bočni zubi Optognath; Bayer-Galenika, Srbija), boja 36, odabrani su za postavljanje u vosku. Proba postavljenih zuba je vršena u dve faze: u prvoj fazi su isprobani prednji zubi i ujedno je izvršena dopunska provera uspostavljenog centralnog položaja donje vilice, kao i položaja kondila. Na osnovu resorpcije i stanja nosećih tkiva, protruzione i lateralne kretnje donje vilice i međuviličnih odnosa načinjena je specifična shema okluzije.

U sledećim postupcima su bočni veštački zubi postavljeni u vosak. Artikulacioni papir debljine $80 \mu \mathrm{m}$, sa dvostranom površinom i različitim bojama (crvena i plava, po odgovarajućoj površini artikulacione hartije), postavljen je u postupku ispitivanja okluzije. Okluzivni kontakti su uspostavljeni kao tripodni - tačkasti kontakti malih dimenzija na strani gde je bezubi greben vilice bio intenzivno resorbovan prema distalnoj granici. Tripodni tačkasti kontakti su uspostavljeni i na zubima antagonistima iz suprotne vilice na toj strani. Kontakti na suprotnoj, levoj strani su formirani u obliku cirkumferencija, tj. manjih površina (Slike 7 i 8 ).

Za vreme simulacije pokreta vilice $\mathrm{u}$ artikulatoru vodeće putanje su formirane u obliku uskih traka orijentisanih upolje od tripodnih, tačkastih kontakata, a takođe kao putanje nalik na trouglove malih dimenzija izvan cirkumferencijalnih površina sheme okluzije na suprotnoj, levoj strani (Slika 9). Okluzivni kontakti su ispitivani u skladu s nagibima kondilnih putanja, odnosno kondilnim vođenjem.

Voštani modeli proteza s veštačkim zubima su zatim postavljeni u usta pacijenta. Obavljena je još jedna provera međuviličnog odnosa u terapijskom centralnom položaju vilice. Provereni su i okluzivni kontakti u centralnom položaju. Artikulaciona hartija je korišćena za označavanje prevremenih kontakata (Slika 10). Okluzivni kontakti su kasnije ispitivani za vreme simuliranja propulzione kretnje i pri lateralnim kretnjama vilice (Slika 11).

Voštani model gornje proteze s postavljenim veštačkim zubima i voštani model donje proteze s postavljenim veštačkim zu- bima su pričvršćeni uz površine radnih modela. Okluzivni kontakti su određeni u skladu s registratima učvršćenim u ustima pacijenta, položajima kondila i kondilnim vođenjem koje je bilo obezbeđeno tokom podešavanja elemenata artikulatora (Slika 12). Voštani modeli proteza sa završenom postavom veštačkih zuba su ponovo vraćeni na radne modele zbog dodavanja faseta na prednjim veštačkim zubima, da bi se uspostavilo konačno prednje vođenje pomoću anteriornog nagriznog grebena, završne obrade u vosku i kivetiranja.

\section{DISKUSIJA}

Prema podacima iz literature, indikovano je uspostavljanje okluzivnih površina u veštačkom zubnom luku u totalnim zubnim protezama tako da bude ostvaren princip simetrije i ravnomerno raspoređenog opterećenja u funkciji stomatognatog sistema i terapiji $[1,2,6]$. Simetrično opterećenje na određenim površinama okluzivnih kosina zuba potrebno je uspostaviti ne samo u položaju maksimalne interkuspidacije, već i za vreme kliznih kretnji i kontakata pri lateralnim kretnjama i u propulziji $[1,2,3,7]$. Ponekad, međutim, postoje indikacije da se modifikuje shema okluzije menjajući položaje kontakata, posebno pri kliženju zuba tokom simulacija lateralnih kretnji. Individualno različita kondilna vođenja na desnoj i na levoj strani kod istog pacijenta već na samom početku stomatoprotetičke terapije mogu zahtevati i modifikovanje položaja kliznih kontakata na okluzivnim površinama veštačkih zuba u odnosu na konvencionalnu shemu kontakata $[2,5,7]$.

U pojedinim slučajevima bi mogli postojati posebni zahtevi, $\mathrm{u}$ vidu formiranja ravnijih kontakata po okluzivnim površinama i kombinovanja specifično proširenih segmenata kontaktnih putanja na kosinama zuba s manje zakošenim i redukovanim segmentima putanja po okluzivnim površinama odgovarajućih naspramnih zuba antagonista, pre svega u uslovima kada postoje izražena resorpcija samo pojedinih segmenata nosećih tkiva i disbalans kondila. Upravo je to razlog što je u ovom radu odstupljeno od uobičajene okluzivne sheme pri postavi veštačkih zuba u akrilatnim protezama pacijenta, u kojima bi kontakti zuba trebalo da budu uspostavljeni po principu jednotačkastih kontakata oko centralne fose, centralne fisure, marginalnih grebenova i nosećih kvržica zuba.

U ovom radu je istaknuta težnja da se obezbedi pravilna i odgovarajuća preraspodela funkcijskih opterećenja na okluzivne površine zuba u veštačkim zubnim lukovima akrilatnih proteza pacijenta, uzimajući u obzir sagledane osobenosti oblika nosećih kvržica. Specifičan raspored okluzivnih kontakata na desnoj strani i razlika u lokalizaciji i shemi uspostavljenih kontakata zuba na levoj i na desnoj strani je u terapiji ovog pacijenta akrilatnim protezama primenjena da bi se preusmerilo vođenje na okluzivnim površinama veštačkih zuba na desnoj strani u centralni položaj i obezbedilo neometano (pravolinijsko) kliženje po kvržicama zuba na levoj strani, sa izuzetkom u odnosu na uniformnu i simetričnu okluzivnu shemu kontakata zuba. Primena specifične sheme okluzije bi trebalo da obezbedi da stres pri delovanjima okluzivnih sila bude na povoljan način raspoređen i prenesen na noseća tkiva, kao i da se ostvari repozicija pri pomeranjima izmenjenog kondila u disfunkciji na radnoj strani $[5,9,10]$.

Ovom pacijentu je izrađen i na akrilatnu protezu dodat nagrizni greben sa izmodelovanim incizalnim ivicama i okluziv- 
nim površinama zuba od kompozitnog materijala zbog korekcije odnosa postojećih donjih prednjih zuba.

Posebno prilagođen raspored okluzivnih kontakata povoljno utiče na smanjenje okluzivnog pritiska prema nosećim tkivima u ustima pacijenta. Kontakti zuba su uspostavljeni na ovakav način da bi se povoljno preusmerilo opterećenje i sprečilo prete- rano izvođenje pokreta u propulziju i lateralne, odnosno lateropropulzione položaje donje vilice. Okluzivna shema po principu uspostavljanja tripodnih i pojedinačno raspoređenih kontakata upotrebljena je da bi se nadomestile razlike u pokretima kondila ovog pacijenta sa disfunkcijom stomatognatog sistema, u nameri da se smanje opterećenja na resorbovane površine grebena. 